\title{
HS-SPME-GC-MS detection of volatile compounds in Myrciaria jabuticaba Fruit
}

\author{
Gerby Giovanna Rondán Sanabria ${ }^{1,2, *}$; Ausberta Jesus Cabezas Garcia ${ }^{2}$; Antonio \\ William Oliveira Lima ${ }^{3}$; Brousett-Minaya Magaly Alejandra ${ }^{4}$; Narendra Narain ${ }^{2}$ \\ 1 Dirección de Investigación, Universidad Tecnológica del Perú (UTP), Av. Tacna y Arica 160, Arequipa, Peru. \\ 2 Laboratory of Flavor and Chromatographic Analysis, Federal University of Sergipe, 49100-000 São Cristóvão, SE, \\ Brazil. \\ 3 Institute of Chemistry, São Paulo University, Av. Prof. Lineu Prestes, 748 - Butantã, 05508-000, São Paulo, SP, \\ Brazil. \\ 4 Facultad de Ciencias Naturales y formales, Universidad Nacional de San Agustin, Av. Independencia s/n, Arequipa, \\ Peru.
}

Received December 10, 2017. Accepted August 13, 2018.

\begin{abstract}
This study was performed to investigate the volatile compounds for the characteristic aroma in jabuticaba fruit distributed in southern and central regions of Brazil. The present work combines headspace solid phase microextraction (HS-SPME) and high resolution gas chromatography-mass spectrometry (GC-MS) techniques to identify and quantify the volatile compounds. The influence of different SPME fibers (CAR/PDMS and DVB/CAR/PDMS) in extraction of volatile compounds was evaluated. The effects of extraction temperature and salt concentration $(\mathrm{NaCl})$ in the extraction medium were studied using the response surface methodology in order to achieve the highest extraction efficiency. The better extraction of volatile compounds was achieved by using a CAR/PDMS fiber and the optimum adsorption conditions were at $42{ }^{\circ} \mathrm{C}$ for $30 \mathrm{~min}$ and $5 \% \mathrm{NaCl}$ concentration. A total of 71 compounds were identified, among these, $57 \%$ were terpenes which was the most representative class of compounds, followed by esters $(19 \%)$, aldehydes $(10 \%)$, alcohols $(5.5 \%)$ and aromatics compounds $(4.4 \%)$ and other organic compounds $2.8 \%$. Limonene and ethyl acetate were the volatile compounds that showed highest relative concentration and these could contribute to the characteristic aroma of the jabuticaba fruit along with other compounds such as $\beta$-pinene, $\delta$-cadinene, linalool, $\beta$-guaiene, and $\alpha$-caryophyllene.
\end{abstract}

Keywords: jabuticaba; Myrciaria; volatile compounds; headspace solid phase microextraction; gas chromatography mass spectrometry.

\section{Introduction}

Jabuticaba is a Brazilian native fruit from the Atlantic rainforest that belongs to the Myrtaceae family, grape-like in appearance and texture. Its economic importance has been continuously growing in Brazil because of the sweet and slightly acidic flavor of the pulp. Jabuticaba is a small fruit, grape-like in appearance and is one of Brazil's richest sources in anthocyanins. The most common varieties are Myrciaria cauliflora (DC) 0 . Berg, Myrciaria jabuticaba (Vell) Berg and jabuticaba-assú. The fruit grows directly on the main trunk and branches, has a diameter verying from 1-4 centimeters, with 1 - 4 large seeds per fruit and richly colorful epicarpio covering the white sweet pulp and jelly-like in appearance (Reynertson et al., 2006). It is mostly consumed as fresh fruit or turned into various industrial products are also availablesuch as juice, jellies, wines and liquors.

The interest of this fruit has grown in recent years because it has in its chemical composition phenolic constituents such as anthocyanins, flavonoids and ellagitannins. The fruit is also reported to possess well defined biological properties including antioxidant and anti-inflammatory activities (Middleton et al., 2000). Although the jabuticaba is a fruit with important functional properties for health the components that give it a pleasant taste and aroma have not yet been investigated. The aroma is one of the most important quality attributes of tropical and subtropical fruits and numerous analytical techniques have been developed to characterize the compounds responsible 
for its aroma quality. Most of the volatile compounds of the fruit are composed of saturated and unsaturated molecules from aliphatic compounds that have functional oxygen groups such as ester, alcohol, acid, aldehyde, ketone or lactone, which originate during the maturation process by different metabolic pathways. A recent study reported that the high sugar content associated with terpenes contribute to result in sweet, acidic and slight resinous flavor of the jabuticaba fruits (Plagemann et al., 2012).

The flavour impact is a complex mixture of volatile organic chemicals and taste contributors. Quality perception cannot be analysed and it is seldom possible to trace the complex composition of flavour and taste. However, one of the most interesting techniques for studying flavour quality is HS-SPME (Souza-Silva et al., 2015). There is growing interest in this field to elucidate whether the flavour profiles of fresh fruits and vegetables are affected by the cultivation system (Vallverdú-Queralt and Lamuela-Raventós, 2016).

The development of fast and simple methods for volatiles extraction is important because it can reduce the sampling time and analysis can be performed quickly. A fast sampling technique that can be adapted for gas chromatography (GC) analysis of volatile compounds is the solid phase microextraction (SPME). This technique has been applied for the analysis of volatile and nonvolatile compounds in liquid and gaseous samples (Arthur and Pawliszyn, 1990) and to analyze the flavor in juices and vegetable oils (Yang and Peppard, 1994). SPME is a pretty fast and reliable technique for the determination of volatile compounds in complex matrices. It iss based on the extraction of analytes from the sample matrix using a fused silica fiber $(1-2 \mathrm{~cm})$, coated with a thin film of absorbent material which in most cases is of polymeric nature. Subsequently, in order to separate and identify the organic compounds, the desorption of analytes is carried out by increasing the temperature, where the fiber is held into the GC injection port for its instrumental analysis (Lasekan and Abbas, 2010). HS-SPME technique has been used to evaluate the pitomba fruit (Talisia esculenta Radlk.) (De Souza et al., 2016); strawberries, raspberries, blackberries and bananas (Ibanez et al., 1998); Bayberry (Cheng et al., 2015); passion fruit, cashew apple, tamarind, guava and acerola (Carasek and Pawliszyn, 2006); grape berry (Parker et al., 2007) and mango (Liu et al., 2013).
In this study a new system was developed consisting of HS-SPME for the capture of volatile compounds on fiber containing different porous material, followed by desorption of volatile compounds onto a system of GC-MS, wherein a capillary column was used to separate the volatile compounds, identify and quantify these compounds present in jabuticaba fruit pulp. The study was performed to select the best fiber for the volatile analysis, along with the optimization of the extraction conditions such as the temperature and ionic strength of extraction media and analyzing the data obtained by response surface methodology interpretation.

\section{Materials and methods}

\section{Sample}

Fresh ripe jabuticaba fruits having no apparent injury or microbial spoilage were purchased from a local market of Aracaju city in the state of Sergipe, Brazil. The fruits were washed with water and disinfected using $1 \%$ sodium hypochlorite solution whereafter the fruits were again washed with water. The pulp of jabuticaba fruit was removed manually using a stainless steel knife. After the extraction of the seed, the pulp and peel were homogenized in a waring blender without addition of water, then it was filtered and the resulting homogenate was kept in polythene bags and stored in a freezer maintained at $-20^{\circ} \mathrm{C}$ until further analysis. For the extraction of volatiles compounds, the samples were thawed at room temperature and diluted with distilled water (Milli-Q Integral Water Purification System) in an aqueous solution of sodium chloride (Sigma Chemical Co., Aldrich Chemical Co.) at different concentrations. The final proportion of pulp and the solution was of 3.5:10.

Selection of SPME fibers in the extraction of volatile compounds

Tests were performed using different fibers such as carboxen/polydimethylsiloxane (CAR/PDMS; $85 \mathrm{\mu m})$ and divinylbenzene/Carboxen/polydimethylsiloxane (DVB/CAR/PDMS; 50/30 $\mu \mathrm{m}$ ), both supplied by Supelco (Bellefonte, PA, USA) and these were evaluated to verify the ability to collect and concentrate the headspace volatiles of jabuticaba homogenate, mainly due to their sorption characteristics. These fibers were exposed to HS using SPME holder in $40 \mathrm{ml}$ vials containing a mixture of $3.5 \mathrm{~g}$ of fruit homogenate and $10 \mathrm{ml}$ of deionized water. The vials were sealed with a polypropylene plug and extraction perfor- 
med for $30 \mathrm{~min}$ at $25{ }^{\circ} \mathrm{C}$ under constant magnetic stirring. After the extraction, SPME fibers were removed from the vials and inserted into the GC injection system (Agilent GC system model 7820A) - MS (Agilent MS model 5975), for the separation and identification of volatiles. Experiments containing only fruit homogenate with distilled water were performed between the extraction processes also to verify the results that there was no interference from earlier runs.

\section{Extraction Conditions}

After the selection of the best SPME fiber for sorption of volatiles of jabuticaba homogenate, the best experimental conditions for the extraction of volatiles by HSSPME were determined. The Response Surface methodology (RSM) was used wherein the independent variables were salt concentration or ionic strength (IS) and extraction temperature (T). The data were interpreted on the basis of the dependent variable being the number of detected peaks (NP). A Central Composite Design (CCD) with two variables at five levels $(-1$, $1.41,0,+1,1.41)$ was used and the center point was replicated six times, totalizing 14 experiments. The experimental conditions in the center point were: salt concentration $15 \% \mathrm{NaCl}$ and $35{ }^{\circ} \mathrm{C}$. The experimental values varied were: $X_{1}=$ ionic strength $(0,5$, $15,26$ and $30 \%)$ and $X_{2}=$ temperature $(25$, $28,35,42$ and $\left.45^{\circ} \mathrm{C}\right)$. For HS-SPME analysis, $3.5 \mathrm{~g}$ of homogenate was mixed with $10 \mathrm{ml}$ aqueous solution of $\mathrm{NaCl}$ at different concentrations in a hermetically sealed $40 \mathrm{~mL}$ vials with a polypropylene plug. Subsequently the mixture was heated at different temperatures $(25,28,35,42$ and $45^{\circ} \mathrm{C}$ ) in thermostatic bath for $15 \mathrm{~min}$ in order to reach thermal equilibrium with constant magnetic stirring. Later the selected fiber was inserted into the vial and was exposed to HS for $\mathbf{3 0}$ minutes to adsorb the volatiles. The SPME fiber was immediately taken to the GC injection port and thermally desorbed for $8 \mathrm{~min}$ at $250^{\circ} \mathrm{C}$ in split mode. The number of detected peaks in each run was used as a response variable of the experimental design and a quadratic model was constructed to describe the observed data.

Chromatographic analysis

Chromatographic analysis was performed using GC-MS system equipped with a DB-5 capillary column (inner diameter: $30 \mathrm{~m} \times$ $0.25 \mathrm{~mm}$, film thickness: $0.25 \mu \mathrm{m}$ ). The oven temperature was programmed initially at 40 ${ }^{\circ} \mathrm{C}$ for $4 \mathrm{~min}$, then increased at the rate of 7 ${ }^{\circ} \mathrm{C} / \mathrm{min}$ to $160{ }^{\circ} \mathrm{C}$ wherein held for $8 \mathrm{~min}$, subsequently the temperature raised at 15 ${ }^{\circ} \mathrm{C} / \mathrm{min}$ up to $250{ }^{\circ} \mathrm{C}$ and maintained for 3 $\mathrm{min}$ at this temperature, totalizing $38 \mathrm{~min}$ of chromatographic analysis. Helium was used as carrier gas at a constant rate of 1.0 $\mathrm{mL} / \mathrm{min}$. The mass spectrometer was operated in scan mode from $29-550 \mathrm{~m} / \mathrm{z}$, at $70 \mathrm{eV}$ ionization.

The identification of volatiles compounds was performed by calculating the linear retention index (LRI) of each compound using a series of alkane standards analyzed under identical conditions as that of the samples and comparing the mass spectrum of the compound peaks with mass spectra library of NIST/EPA (NIH version 2.0). The values of LRI of each compound were also compared with those described in the literature as well as from the data base of compounds identification in our laboratory wherein standards analysis was performed in identical analytical conditions. The relative concentrations of individual components were expressed as a percentage of the relative peak area to that of the total peak area.

\section{Statistical analysis}

The statistical significance of the model was evaluated by analysis of variance (ANOVA) with significance level of $5 \%$ ( $p<$ 0,05). Statistica V.7 (Statsoft Inc., Tulsa, OK, USA) was used in order to generate ANOVA and response surface methodology interpretations.

\section{Results and discussion}

Optimization of extraction conditions using HS-SPME

The extraction time, extraction temperature, mass of the sample and sodium chloride concentration are the factors which influence the vapor pressure of the volatiles in the headspace. The optimization method evaluated only considered the effect of the salt addition associated with the adsorption temperature, while the other variables remained constant during the tests. The response was evaluated to determine the best extraction conditions for HS-SPME based on the analysis of chromatograms relating to higher number of identified volatile compounds and the intensity of the response. However, before optimization of the extraction conditions, the adsorption profile of the 3 SPME fibers was evaluated and in later experiments only the selected fiber was used.

\section{SPME Fibers}

The selection of the most suitable SPME fiber depends on the target compounds and the sample under study (Gioti et al., 2007). 
Two semi polar fibers - CAR/PDMS and DVB/CAR/PDMS were tested, and compared individually. The results reported in Figure 1A show that the CAR/PDMS fiber resulted in a better profile having high extraction efficiency of volatile compounds in jabuticaba as it resulted in greater number of detected compounds and their signal strength. CAR/PDMS fiber coating is most suitable for the extraction of small volatile molecules. The sensitivity of this fiber into smaller molecules, such as esters, acids and non-polar compounds, allows the extraction of a broad range of aromatic compounds (Érica et al., 2017). The compounds with the highest intensity were the ethyl acetate (22.04\%) and limonene (11.47\%) (Figure 1B). Furthermore, the main components adsorbed were the terpenoids, including $\alpha$-pinene, $\beta$ pinene, $\beta$-ocimenoe, $\beta$-caryophyllene, $\alpha$ - muurolene, $\delta$-cadinene, calamenene and limonene, which could be responsible for the characteristic aroma of the fruit. Considering better results obtained by using the CAR/PDMS fiber, it was selected for further studies of the characterization of volatile compounds of jabuticaba fruit.

Effects of the combination of sodium chloride and extraction temperature

The response surface methodology (RSM) is a powerful tool that enables quickly and efficiently to interpret the data while having only a minimum number of experiments. A total of 14 experiments (Table 1) were performed in random combinations of temperature and ionic strength to check the effects of the combination of sodium chloride and the extraction temperature, the results are presented in Figure 2.
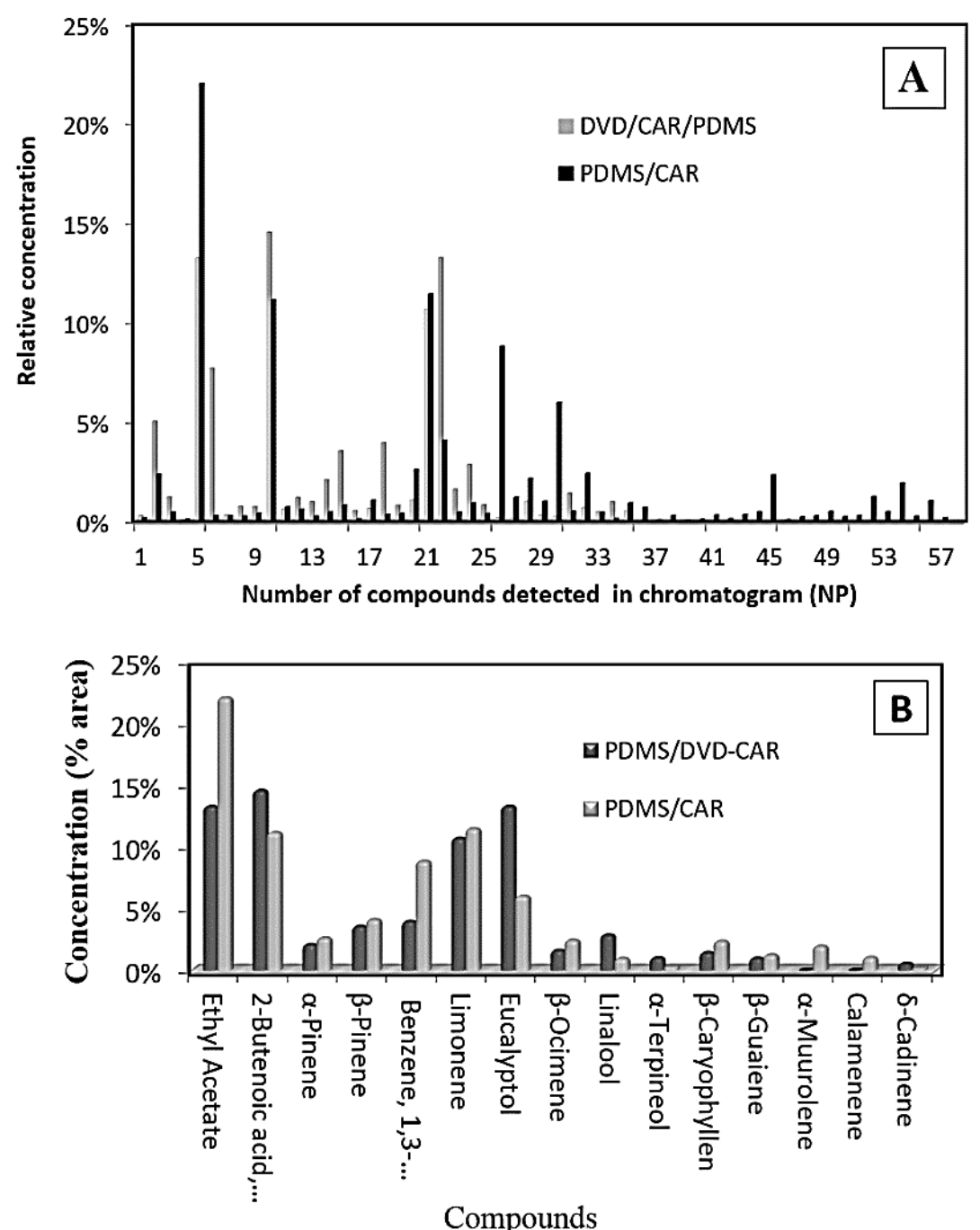

Figure 1. Influence of the fiber (PDMS/DVD/CAR and PDMS/CAR) on the extraction of volatile compounds from jabuticaba homogenate: A - Relative concentration $(\%)$ of the number of detected peaks; B - Concentration (\%) of the main detected compounds. 
Table 1

Description of independent variables analyzed in Central Composite Design showing the experimental and predicted values of number of peaks in chromatogram

\begin{tabular}{|c|c|c|c|c|c|c|}
\hline \multirow[b]{2}{*}{ Experiment/N } & \multicolumn{2}{|c|}{ Coded Levels } & \multicolumn{2}{|c|}{ Independent variables } & \multicolumn{2}{|c|}{ Peak number } \\
\hline & $\mathrm{X} 1$ & $\times 2$ & IS & $\mathrm{T} /{ }^{\circ} \mathrm{C}$ & Experimental & Predicted \\
\hline 1 & -1 & -1 & 5 & 28 & 53 & 55.011 \\
\hline 2 & -1 & 1 & 5 & 42 & 89 & 87.052 \\
\hline 4 & 1 & 1 & 26 & 42 & 81 & 81.741 \\
\hline 5 & 0 & 0 & 15 & 35 & 63 & 62.167 \\
\hline 6 & 0 & 0 & 15 & 35 & 63 & 62.167 \\
\hline 8 & -1.414 & 0 & 0 & 35 & 78 & 78.525 \\
\hline 9 & 1.414 & 0 & 30 & 35 & 75 & 71.722 \\
\hline 10 & 0 & -1.414 & 15 & 25 & 44 & 39.824 \\
\hline 11 & 0 & 1.414 & 15 & 45 & 83 & 84.423 \\
\hline 12 & 0 & 0 & 15 & 35 & 62 & 62.167 \\
\hline 13 & 0 & 0 & 15 & 35 & 62 & 62.167 \\
\hline
\end{tabular}

(-1.41) Low level, (1.41) High level, (0) Central point, (IS) lonic Strength and (T) Temperature.

The response surface (Figure 2A) was obtainned using mathematical model expressed in coded variables by interpreting the data using Statistica software, which resulted in the following equation:

$Y_{(N P)}=62.1669-2.4050 X_{1}+15.7700 X_{2}+6.4800$

$X_{1} X_{1}-0.0150 X_{2} X_{2}-0.2500 X_{1} X_{2}$ (eq.1)

Salt concentration $\left(X_{1}\right)$ and temperature $\left(X_{2}\right)$, as well as quadratic term ionic strength $\left(X_{1} X_{1}\right)$ were significant $(p<0.05)$ and these influenced the volatile compounds extraction as shown in the Pareto Chart (Figure 1B). It can be observed that the temperature was the most significant parameter $(p<0.05)$, showing a strong positive influence. The model had a value $R$ $=0.97$, considered appropriate for extraction and values greater than 0.90 are considered statistically significant. It was also observed that the maximum number of detected compounds were found at the surface of the peak, this fact could indicate the best experimental conditions. According to this model, the best combination of extraction was at $42{ }^{\circ} \mathrm{C}$ with $5 \% \mathrm{NaCl}$, wherein 89 volatiles compounds were separated as shown in the chromatogram (Figure 3).

CCD was an important tool in the optimization of the extraction method of volatiles because traditional optimization methods evaluate only the effect of a variable while keeping the other valuables constant during the experiments. However, this type of test suffers from the limitation that it does not take into account as to what would happen if other variables also change. The experimental design (response surface + central composite design) used in this study allowed the estimation of the effects of two variables simultaneously.

The experimental design used in this work has been earlier used in studies for the extraction of volatile compounds from several fruits such as cupuassu (Oliveira et al., 2004), orange juice (Mirhosseini and Tan, 2009; Charve et al., 2011), cherimoya (Annona cherimila), soursop (Annona muricata) (Ferreira et al., 2009; Cheong, et al., 2011) and umbu (Spondias tuberosas) (Galvão et al., 2011).

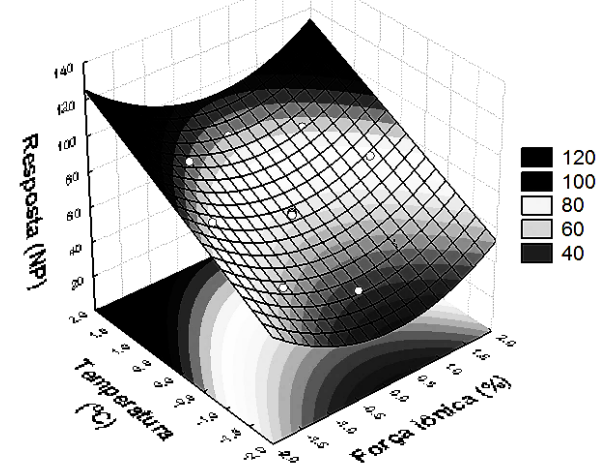

(A)

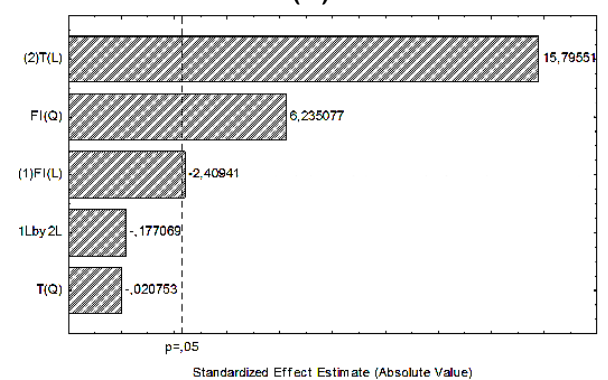

(B)

Figure 2. A - Response surface generated by quadratic model (eq. 1) in the optimization of the temperature (T, ${ }^{\circ} \mathrm{C}$ ) and ionic strength (IS, \%) in the extraction of volatile compounds of jabuticaba fruit using HS-SPME; B Pareto chart showing statistically significant variables $(p<0.05)$ influencing the response during the extraction of volatile compounds.

Identification and quantification of volatile compounds

Figure 3 shows the typical total ion chromatogram obtained under best extrac- 
tion conditions. The 15 compounds which are numbered in the chromatogram represent the compounds with higher intensity. Table 2 shows the data on areas of the detected peaks, expressed in percentage, for the different compounds that were used to indicate the relative concentration of each substance along with their characteristic odor note. A total of 71 compounds were identified according to the similarity of their mass spectra and by comparison with the standard values described in the literature.

Among the identified compounds, 41 $(57.7 \%)$ were terpenes, $14(19.7 \%)$ esters, 7 $(9.90 \%)$ aldehydes, four $(5.60 \%)$ alcohols, three $(4.20 \%)$ aromatic compounds. The compounds that showed the highest concentration were: limonene (17.7\%) followed by ethyl acetate $(10.7 \%), 1,3-$ dichlorobenzene $(9.7 \%)$, eucalyptol $(5.8 \%)$ caryophyllene $(5.0 \%)$, ocimene $(3.6 \%), \beta-$ pinene $(3.0 \%), \quad \beta$-guaiene $(2.9 \%)$, 2butanoic acid ethyl ester (2.5\%) and $\alpha$ pinene $(2.2 \%)$.

Plagemann et al. (2012) identified only 45 volatile compounds from jabuticaba pulp, among which the $\beta$-pinene, $\delta$-cadinene, 2phenylethanol and linalool were the most prominent compounds in the fruit flavor. These authors also attributed to terpenes as the major contributors to the flavor, indicating that the most odorous compounds were $\beta$-caryophyllene and limonene.
In the essential oil of jabuticaba leaves (Myrciaria cauliflora), Duarte et al. (2010) identified compounds similar to those detected in this study, including $\alpha$-pinene, $\beta$-pinene, limonene, $\delta$-elemene, $\beta$-elemene, $\beta$-caryophyllene, $\delta$-cadinene and $\alpha$ muurolene, which may be responsible for the aroma of the fruit.

Comparing the results of this study with those found in other typical fruits of the Amazon of the same genus (Myrciaria), there was similarity in the presence of several compounds, such as in the fruit of camu-camu (Myrciaria dúbia) showing apinene (17.5), limonene (10.8), $\beta$ caryophyllene and $\beta$-pinene were reported. The $\beta$-pinene is also the most important volatile compound in umbu-cajá (Spondias cintherea) (Franco and Shibamoto, 2000). In pitanga (Eugenia inflora L.) fruit, the presence of $\beta$-pinene and $\beta$-ocimene as important constituents for aroma of the fruit was also reported (Oliveira et al., 2006). While chinese bayberry had a stronger "pine" odor, which is caused mainly by $\alpha$ pinene (Cheng et al., 2015).

Based on the identification and quantifycation of volatile compounds present in the jabuticaba fruit, it could be concluded that the main compounds such as limonene, ethyl acetate, eucalyptol, caryophyllene, ocimene, $\beta$-pinene and $\alpha$-pinene could contribute to the characteristic aroma quality of this fruit.

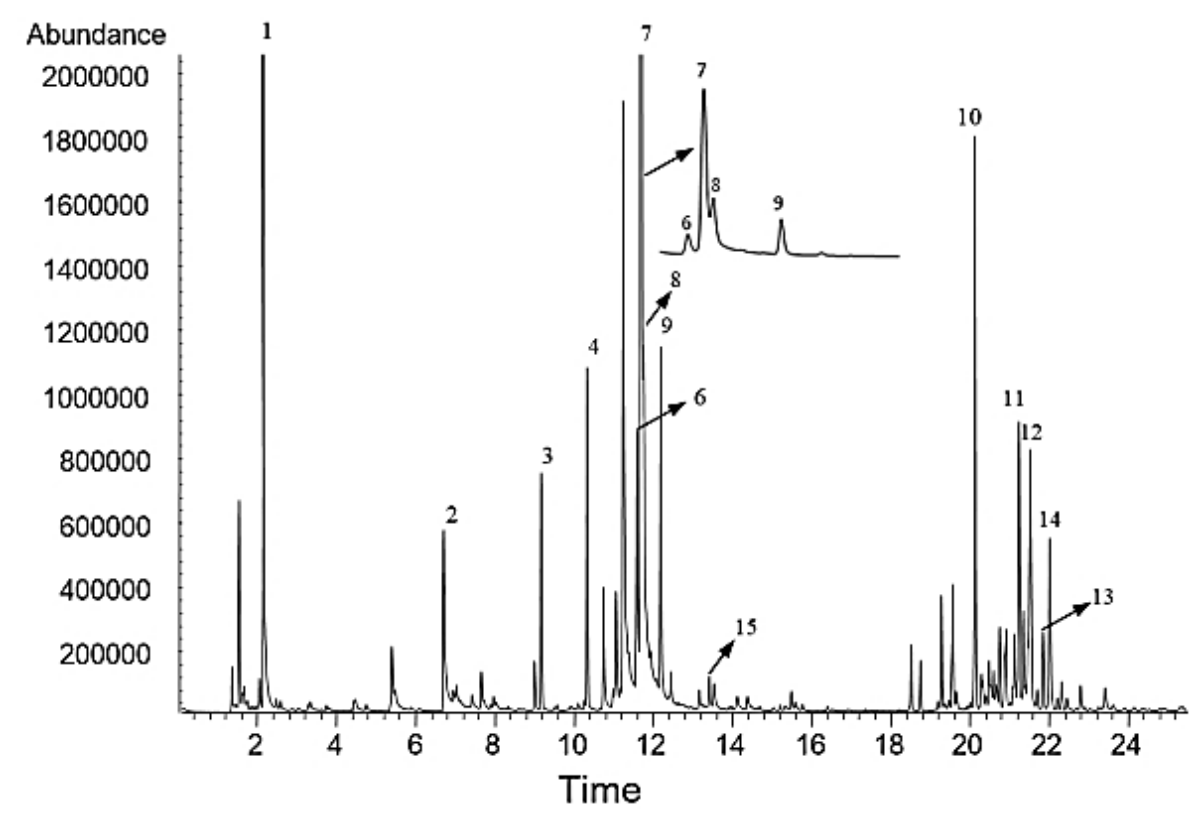

Figure 3. Representative chromatogram of the volatile compounds of jabuticaba homogenate. The predominant peaks and the most striking aroma compounds are numbered as follows: Ethyl acetate (1), 2-butenoic acid, ethyl ester, (E) (2), a-pinene (3), $\beta$ - Pinene (4), Benzene 1,3-dichloro- (5), Benzene, 1-methyl-3-(1-methylethyl) - (6), limonene (7), Eucalyptol (8), $\beta$-ocimene, (9), $\beta$-caryophyllene (10), $\beta$ - guaieno (11), $\alpha$-muuroleno (12), $\delta$-cadinene (13), calameneno (14) and linalool (15). 
Table 2

Volatile compounds identified in jabuticaba fruit pulp

\begin{tabular}{|c|c|c|c|c|c|}
\hline \multirow[b]{2}{*}{ Compoundsa } & \multicolumn{2}{|r|}{ LRI } & \multirow{2}{*}{$\begin{array}{c}\text { Relative } \\
\text { area } \\
\text { percent }\end{array}$} & \multirow[b]{2}{*}{ Odor descriptionc } & \multirow{2}{*}{$\begin{array}{l}\text { Identifi- } \\
\text { cationd }\end{array}$} \\
\hline & bDB-5 & Ref. & & & \\
\hline $\begin{array}{l}\text { Alcohols } \\
\text { Ethanol }\end{array}$ & 369,59 & ---- & $1,75 \%$ & sweet & MS \\
\hline $\begin{array}{l}\text { Ethanol } \\
\text { 3-methyl-1-butanol }\end{array}$ & 730,45 & $1,2,3,7$ & $0,05 \%$ & whiskey, malt, burnt & MS, LRI \\
\hline (Z) -3-Hexenol & 857,60 & $1,2,3,7$ & $0,21 \%$ & grass & MS, LRI \\
\hline 1-Hexanol & 871,34 & $1,2,3,10$ & $0,18 \%$ & resin, flower, green & MS, LRI \\
\hline \multicolumn{6}{|l|}{ Aldehydes } \\
\hline 3-Methyl-1-butanal & 581,58 & --- & $0,12 \%$ & & MS \\
\hline Pentanal & 603,85 & -- & $0,11 \%$ & almond, malt, pungent & MS \\
\hline Hexanal & 801,18 & $1,3,4,5,12$ & $0,79 \%$ & grass, tallow, fat & MS, LRI \\
\hline (E)-2-Hexenal & 854,72 & $1,3,4,5$ & $0,18 \%$ & green, leaf & MS, LRI \\
\hline Nonanal & 1105,58 & $3,4,7,10,12$ & $0,39 \%$ & fat, citrus, green & MS, LRI \\
\hline Decanal & 1206,82 & $1,3,4,6,7,12$ & $0,07 \%$ & soap, orange peel, tallow & MS, LRI \\
\hline \multicolumn{6}{|l|}{ Aromatic compounds } \\
\hline Styrene & 890,20 & $4,10,11$ & $0,14 \%$ & balsamic, gasoline & MS, LRI \\
\hline Benzaldehyde & 961,45 & $1,3,4,7,12$ & $0,02 \%$ & almond, burnt sugar & MS, LRI \\
\hline 1,3-dichlorobenzene & 1011,55 & & $9,70 \%$ & & MS \\
\hline p-cymene & 1025,73 & $3,6,11,16$ & $3,13 \%$ & solvent, gasoline, citrus & MS, LRI \\
\hline Esters & & & & & \\
\hline $\begin{array}{l}\text { Ethyl Acetate } \\
\text { Ethyl propanoate }\end{array}$ & $\begin{array}{l}503,21 \\
711,06\end{array}$ & 8 & $\begin{array}{c}10,71 \% \\
0,05 \%\end{array}$ & $\begin{array}{l}\text { pineapple } \\
\text { Fruit }\end{array}$ & MS \\
\hline Propyl acetate & 713,12 & 8 & $0,11 \%$ & celery, ethereal, fruity, pear, & MS LRI \\
\hline Methyl (E)-2-butenoate & 762,14 & 3 & $0,24 \%$ & powerful, raspberry & MS \\
\hline 2-Methylpropyl acetate & 773,63 & 3.-- & $\begin{array}{l}0,24 \% \\
0,07 \%\end{array}$ & fruit, apple, banana & MS \\
\hline Ethyl butanoate & 803,98 & $2,3,6,8$ & $0,44 \%$ & apple & MS, LRI \\
\hline Ethyl (E)-2-butenoate & 846,42 & 3,7 & $2,48 \%$ & Fruity & MS, LRI \\
\hline 3-methylbutyil acetate & 879,47 & --- & $0,39 \%$ & banana & MS \\
\hline Methyl (E) -2-hexanoate & 968,28 & $9,8,10$ & $0,08 \%$ & & MS, LRI \\
\hline Ethyl hexanoate & 1001,02 & $2,3,7,8,9$ & $0,21 \%$ & apple peel, fruit & MS, LRI \\
\hline (Z)-3-hexenyl acetate & 1008,73 & $7,8,11$ & $0,22 \%$ & Unripe banana, fruit, green & MS, LRI \\
\hline (Z)-3-Hexenyl butanoate & 1187,44 & 10 & $0,09 \%$ & wine, green & MS, LRI \\
\hline Ethyl octanoate & 1197,93 & 2,3 & $0,09 \%$ & fruit, fat, floral, pear & MS, LRI \\
\hline Methyl 3-phenylpropenoate & 1387,43 & 11 & $0,08 \%$ & strawberry & MS, LRI \\
\hline Ether & & & & & \\
\hline Ethyl ether & 395,29 & -.-- & $0,19 \%$ & & MS \\
\hline Ketones & & & & & \\
\hline 2-Heptanone & 892,56 & 11 & $0,10 \%$ & soap & MS, LRI \\
\hline Terpenoids & & & & & \\
\hline Tricyclene & 927,89 & 3 & $0,49 \%$ & & MS, LRI \\
\hline a-Pinene & 934,01 & $1,4,3,6$ & $2,15 \%$ & Terpenic, woody & MS, LRI \\
\hline Sabinene & 974,44 & $3,6,7,13$ & $0,08 \%$ & pepper, turpentine, wood & MS, LRI \\
\hline$\beta$-Pinene & 976,80 & $1,3,4,13$ & $2,98 \%$ & Sweet, green & MS, LRI \\
\hline$\beta$-myrcene & 992,14 & $3,6,7$ & $1,35 \%$ & Herbaceous, woody & MS, LRI \\
\hline $\begin{array}{l}\text { a-Phellandrene } \\
\text { Limonene }\end{array}$ & $\begin{array}{l}1004,30 \\
1029,99\end{array}$ & $\begin{array}{l}3,6 \\
1,3,4,6,12,13\end{array}$ & $\begin{array}{c}1,41 \% \\
17,71 \%\end{array}$ & $\begin{array}{l}\text { Citrus, spicy } \\
\text { Citrus, terpenic }\end{array}$ & $\begin{array}{l}\text { MS, LRI } \\
\text { MS, LRI }\end{array}$ \\
\hline $\begin{array}{l}\text { Limonene } \\
\text { Eucalyptol }\end{array}$ & $\begin{array}{l}1029,99 \\
1032,28\end{array}$ & $\begin{array}{l}1,3,4,6,12,13 \\
5,13,16\end{array}$ & $\begin{array}{c}17,71 \% \\
5,79 \%\end{array}$ & $\begin{array}{l}\text { Citrus, terpenic } \\
\text { mint, sweet }\end{array}$ & $\begin{array}{l}\text { MS, LRI } \\
\text { MS, LRI }\end{array}$ \\
\hline (E)- $\beta$-Ocimene & 1050,18 & $3,6,4,13$ & $3,57 \%$ & sweet, herb & MS, LRI \\
\hline$y$-Terpinene & 1060,63 & $3,4,6$ & $0,34 \%$ & gasoline, turpentine & MS, LRI \\
\hline Terpinolene & 1089,88 & $3,6,12$ & $0,16 \%$ & Lime, terpenic & MS, LRI \\
\hline Linalool & 1100,45 & $1,3,7,10,13$ & $0,32 \%$ & flower, lavender & MS, LRI \\
\hline $1,3,8$-p-Menthatriene & 1132,22 & $3,6,11$ & $0,27 \%$ & & MS, LRI \\
\hline (4E,6Z)-allo-Ocimene & 1143,70 & 5,6 & $0,25 \%$ & Green, fresh & MS, LRI \\
\hline a-Terpineol & 1193,52 & 3,7 & $0,21 \%$ & oil, anise, mint & MS, LRI \\
\hline$\delta$-Elemene & 1343,45 & $1,11,14$ & $0,61 \%$ & wood & MS, LRI \\
\hline$\alpha$-Cubebene & 1355,82 & $1,5,6$ & $0,45 \%$ & herb, wax & MS, LRI \\
\hline a-Copaene & 1378,82 & $1,3,5,6$ & $0,09 \%$ & Woody, spicy & MS, LRI \\
\hline$\beta$-Cubebene & 1383,31 & --- & $0,99 \%$ & & MS \\
\hline$\beta$-elemene & 1398,23 & $3,4,11,13,15$ & $1,41 \%$ & herb, wax, fresh & MS, LRI \\
\hline$\beta$-Caryophyllene & 1429,10 & $1,4,3,5$ & $5,01 \%$ & Spicy, woody & MS, LRI \\
\hline Aromadendrene & 1438,10 & 16 & $0,36 \%$ & Dusty, honey, wood & MS, LRI \\
\hline a-Guaiene & 1440,14 & 11,15 & $0,25 \%$ & wood, balsamic & MS, LRI \\
\hline$\beta$-Gurjunene & 1444,12 & 6 & $0,21 \%$ & & MS, LRI \\
\hline$\beta$-farnesene & 1448,81 & 11 & $0,47 \%$ & wood, citrus, sweet & MS,LRI \\
\hline a-Elemene & 1454,94 & 15 & $0,38 \%$ & wood & MS, LRI \\
\hline Allo-Aromadendrene & 1459,36 & 5,14 & $0,36 \%$ & wood & MS,LRI \\
\hline a-Caryophyllene & 1463,50 & $3,5,14$ & $0,80 \%$ & wood & MS, LRI \\
\hline$y$-Muurolene & 1472,28 & $3,6,5,16$ & $1,33 \%$ & herb, wood, spice & MS, LRI \\
\hline Eremophilene & 1484,32 & 3,6 & $0,84 \%$ & & MS, LRI \\
\hline Germacrene D & 1490,50 & $3,6,13,14$ & $2,92 \%$ & wood, spice & MS, LRI \\
\hline Valencene & 1496,47 & 3,11 & $1,00 \%$ & green, oil & MS, LRI \\
\hline$\alpha$-Selinene & 1499,12 & $3,6,13$ & $0,20 \%$ & & MS, LRI \\
\hline Epizonarene & 1502,28 & 16 & $0,62 \%$ & & MS,LRI \\
\hline a-Muurolene & 1505,26 & 13,14 & $3,92 \%$ & wood & MS, LRI \\
\hline y-Cadinene & 1513,49 & $1,5,16$ & $0,27 \%$ & wood & MS, LRI \\
\hline$\delta$-Cadinene & 1520,29 & $3,5,6,13$ & $0,83 \%$ & thyme, medicine, wood & MS, LRI \\
\hline Calamenene & 1528,06 & 3,11 & $2,20 \%$ & herb, spice & MS, LRI \\
\hline Naphthalene, 1,2,3,4,4a,7-hexa- & 1537,04 & - & $0,15 \%$ & & MS \\
\hline $\begin{array}{l}\text { hydro-1,6-dimethyl-4-(1-methylethyl)- } \\
\text { Germacrene B }\end{array}$ & 1564,31 & $1,10,11,14$ & $0,27 \%$ & wood, earth, spice & MS,LRI \\
\hline Caryophyllene oxide & 1593,21 & $1,3,5$ & $0,38 \%$ & herb, sweet, spice & MS, LRI \\
\hline $\begin{array}{l}\text { Saturated hydrocarbons } \\
\text { n-Hexane }\end{array}$ & 478,80 & ----- & $0,26 \%$ & Alkane & MS \\
\hline
\end{tabular}

a Compounds are listed in their elution order on a DB-5 column;

b LRI: Linear retention indices on column (DB-5) determined with n-alkanes and literature and from the data-base of our laboratory;

c Odor description based on the Leffingwell's Flavor-Base (Leffingwell, 2007) and Flavornet (http://www.flavornet.org/flavornet.html);

d Identification method: MS = mass spectrum; LRI is compared with references from standards or literature values as well as from the data base of Volatile compounds analyzed in our laboratory;

Ref: 'Érica et al., (2017); ${ }^{2}$ Boulanger and Crouzet (2001); ${ }^{3 P}$ Pino (2012); ${ }^{4}$ Cheng et al. (2015); ${ }^{5}$ Porat et al. (2011); 6 Liu et al. (2013); ${ }^{7}$ Lasekan et al. (2013); ${ }^{8} \mathrm{Christof}$ et al., (2014); $9 \mathrm{Márquez}$ et al. (2011); ${ }^{10} \mathrm{Liqin}$ et al., (2017); ${ }^{11}$ Acree and Arn (2004); 12Cuevas et al. (2016); 13Plagemann et al. (2012); 14Duarte et al. (2010); 15 Huang et al. (2009); and 16Parker et al. (2007). 


\section{Conclusions}

The combination of HS-SPME technique for capture and GC-MS system for identification of volatile compounds in jabuticaba fruit resulted in identification of a large number of volatile compounds belonging to the organic classes of terpenes, esters, aldehydes, alcohols and aromatic compounds, many of these have not been reported earlier. Among the 2 SPME fibers (CAR/PDMS and DVB/CAR/ PDMS) evaluated for the capture of volatile compounds, the fiber CAR/PDMS resulted in higher number of compounds in jabticaba fruit. Based on this study, it could be concluded that the combination of HSSPME with GC-MS is suitable for the extraction of volatile compounds from jabuticaba fruit. A large number of esters and terpenic compounds could be responsible for the typical aroma of the jabuticaba fruit, the principal compounds being limonene, ethyl acetate, eucalyptol, caryophyllene, ocimene, $\beta$-pinene and $\alpha$ pinene.

Based on the data obtained, the authors recommended further studies taking into accounts the harvest season. In addition to chromatography gases coupled with mass spectroscopy analysis olfactory to confirm the volatile compounds responsible for the aroma of the fruit.

\section{Acknowledgments}

All authors thank the financial support provided from the project, National Institute of Science and Technology (INCT) for Tropical Fruits from CNPq, Brazil offered for promoting research work undertaken in this study. The co-authors Gerby and Ausberta thank the CAPES (Ministry of Education, Brazil) for providing fellowship to her.

\section{References}

Acree, T.; Arn, H. 2004. Gas chromatography olfactometry (GCO) of natural products Sponsored by DATU Inc. Flavornet retrieved from: http://www.flavornet.org.

Arthur, C.L.; Pawliszyn, J. 1990. Solid phase microextraction with termal desorption using fused sílica optical fibers. Analytical Chemistry 62: 2145 2148.

Boulanger, R.; Crouzet, J. 2001. Identification of the aroma components of acerola (Malphigia glabra L.): free and bound flavor compounds. Food Chemistry 74: 209-216.

Carasek, E.; Pawliszyn, A. 2006. Screening of tropical fruit volatile compounds using Solid-Phase Microextraction (SPME) fibers and internally cooled SPME fiber. Journal Agricultural and Food Chemistry 54: 8688-8696.

Charve, J.; Chen, Ch.; Hegeman, A.D.; Reineccius, G.A. 2011. Evaluation of instrumental methods for the untargeted analysis of chemical stimuli of orange juice flavour. Journal of Flavour and Fragrance 26: 429-440.

Cheng, H.; Chen, J.; Chen, S.; Wu, D.; Liu, D.; Ye, X. 2015. Characterization of aroma-active volatiles in three Chinese bayberry (Myrica rubra) cultivars using GC-MS-olfactometry and an electronic nose combined with principal component analysis. Food Research International 72: 8-15.

Cheong, K.W.; Tan, C.P.; Mirhosseini, H.; Chin, S.T.; Man, Y.B.C.; Hamid, N.S.A. et al. 2011. Optimization of equilibrium headspace analysis of volatile flavor compounds of malaysian soursop (Annona muricata): Comprehensive two-dimensional gas chromatography time-of-flight mass spectrometry (GCGC-TOFMS). Food Chemistry 125: 1481-1489.

Christof, B.S.; Tara, G., Reinhold, C. 2014. Influence of harvest maturity and fruit logistics on pineapple (Ananas comosus [L.] Merr.) Volatiles assessed by headspace solid phase microextraction and gas chromatography-mass spectrometry (HS-SPMEGC/MS). Food Chemistry 150: 382-391.

Cuevas, F.J.; Moreno-Rojas, J.M.; Arroyo,F.; Daza, A.; Ruiz-Moreno, M.J. 2016. Effect of management (organic vs conventional) on volatile profiles of six plum cultivars (Prunus salicina Lindl.). A chemometric approach for varietal classification and determination of potential markers. Food Chemistry 199: 479-484.

De Souza, M.P.; Bataglion, G.A.; da Silva, F.M.A.; de Almeida, R. A.; Paz, W.H.P.; Nobre, T.A.; Marinho, J.V.N.; Salvador, M.J.; Fidelis, C.H.V.; Acho, L.D.R.; de Souza, A.D.L.; et al. 2016. Phenolic and aroma compositions of pitomba fruit (Talisia esculenta Radlk.). Food Research International 87: 87-94.

Duarte, R.A.; Santos, S.C.; Seraphin, J.C.; Ferri, P.H. 2010. Environmental influence on phenols and essential oils of Myrciaria cauliflora leaves. Journal of the Brazilian Chemical Society 21(9): 1672-1680.

Érica, A.; Souza, S.; Saboia, G.; Nina, C.J.; Hoffmann, C.; Dos Santos, R.S.I.; Geraldo, L. G. Soares, G.L.; Zini, C.A. 2017. Development of a HS-SPME-GC/MS protocol assisted by chemometric tools to. Talanta 175: 9-20.

Ferreira, L.; Perestrelo, R.; Câmara, J.S. 2009. Comparative analysis of the volatile fraction from Annona cherimola Mill. cultivars by solid-phase microextraction and gas chromatographyquadrupole mass spectrometry detection. Talanta 77: 1087-1096

Franco, M.R.B.; Shibamoto, T. 2000. Volatile composition of some Brazilian fruits: Umbu-cajá (Spondias cytherea), camu-camu (Myrciaria dubia), araçá-boi (Eugenia stipitata), and cupuaçu (Theobroma grandiflorum). Journal of Agricultural and Food Chemistry 48: 1263-1265.

Galvão, S.M.; Narain, N.; dos Santos, P.S.M.; Nunes, M.L. 2011. Volatile compounds and descriptive odor attributes in umbu (Spondias tuberosa) fruits during maturation. Food Research International 44: 1919-1926.

Gioti, M.E.; Fiamegos, C.Y.; Skalkos, C.D.; Atalikas, D.C. 2007. Improved method for the in vitro assessment of antioxidant activity of plant extracts by headspace solid-phase microextraction and gas chromatography-electron capture detection. J. of Chromatography A 1152(1): 150-155.

Huang, B.; Qin, L. Chu, Q.; Zhang, Q.; Gao, L.; Zheng, H. 2009. Comparison of headspace SPME with hydrodistillation and SFE for analysis of the volatile components of the roots of Valeriana officinalis var. latifolia. Chromatographia 69: 489-496.

Ibanez, E.; Lopez-Sebastian, S.; Ramos, E.; Tabera, J. Reglero, G. 1998. Analysis of volatile fruit components by headspace solid-phase microextraction, Food Chemistry 63: 281-286.

Lasekan, O.; Khatib, A.; Juhari, H.; Patiram, P.; Lasekan, S. 2013. Headspace solid-phase microextraction gas chromatography-mass spectrometry determination of volatile compounds in different 
varieties of African star apple fruit (Chrysophillum albidum). Food Chemistry 141: 2089-2097.

Lasekan, O.; Abbas, K. 2010. Flavour chemistry of palm toddy and palm juice: a review. Trends in Food Science \& Technology 21: 494-501.

Leffingwell. 2007. Flavor Base. Leffingwell \& Associates. Available in: www.leffingwell.com/flavbase.htm

Liqin, Y.; Chunxiang, Y.; Weidong, L.; Jiangbo, H.; Sun, M.; Jingru, Z.; Zhongshuang, Z. 2017 Evaluation of volatile compounds from Chinese dwarf cherry (Cerasus humilis (Bge.) Sok.) germplasms by headspace solid-phase microextraction and gas chromatography-mass spectrometry. Food Chemistry 217: 389-397.

Liu, F.X.; Fu, S.F.; Bi, X.F.; Chen, F. et al. 2013. Physicochemical and antioxidant properties of four mango (Mangifera indica L.) cultivars in china. Food Chemistry 138: 396-405.

Márquez, C.J.; Jimenez, A.M.; Osorio, C.; Cartagena, J.R. 2011. Volatile compounds during the ripening of colombian soursop (Annona muricata L. cv. Elita). Vitae, Revista de la Facultad de Química Farmacéutica 18(3):245-250.

Middleton, E.J.R.; Kandaswami, C.; Theoharides, T.C. 2000. The Effects of Plant Flavonoids on Mammalian Cells: Implications for Inflammation, Heart Disease, and Cancer. Pharmacological Reviews 52: 673-751.

Mirhosseini, H.; Tan, C.P. 2009. Response surface methodology and multivariate analysis of equilibrium headspace concentration of orange beverage emulsion as function of emulsion composition and structure. Food Chemistry 115: 324-333.

Oliveira, L.A.; Lopes, B.R.; Fernando, A.; Cabral, M.N.; Eberlin. 2006. Volatile compounds from pitanga fruit (Eugenia uniflora L.). Food Chemistry 99: 1-5.

Oliveira, M.A.; Pereira, N.R.; Marsaioli, Jr.A.; Augusto, F. 2004. Studies on the aroma of cupuassu liquor by headspace solid-phase microextraction and gas chromatography. Journal of Chromatography A 1025: 115-124.

Parker, M.; Pollnitz, A.P.; Cozzolino, D.; Leigh-Francis, I.; Herderich, M.J. 2007. Identification and quantification of a marker compound for 'pepper' aroma and flavor in shiraz grape berries by combination of chemometrics and gas chromatography-mass spectrometry. Journal of Agricultural and Food Chemistry 55: 5948-5955.

Pino, J.A. 2012. Odour-active compounds in mango (Mangifera indica L. cv. Corazón). International Journal of Food Science and Technology 47: 1944 1950.

Plagemann, I.; Krings, I.; Berger, R.G.; Maróstica, Jr. M.R. 2012. Volatile constituents of jabuticaba (Myrciaria jabuticaba (Vell.) O. Berg) fruits. Journal of Essential Oil Research 24(1): 45-51.

Porat, R.; Tietel, Z.; Zippori, I.; Dag, A. 2011. Aroma volatile compositions of high-and low-aromatic guava varieties. Journal of the Science and Food Agriculture 91: 2794-2798.

Reynertson, K.A.; Wallace, A.M, Adachi, S.; Gil, R.R.; Yang, H.; Basile, M.J. 2006. Bioactive depsides and anthocyanins from jabuticaba (Myrciaria cauliflora). Journal of Natural Products 69: 12281230 . .

Souza-Silva, É.A.; Gionfriddo, E.; Pawliszyn, J. 2015. A critical review of the state of the art of solid-phase microextraction of complex matrices II. Food analysis. TrAC Trends in Analytical Chemistry 71: 236-248.

Vallverdú, Q.A.; Lamuela-Raventós, R.M. 2016. Foodomics: A new tool to differentiate between organic and conventional foods. Electrophoresis. 13:1784-94.

Yang, X.; Peppard, T. 1994. Solid-phase microextraction for flavor analysis. Journal Agricultural of Food Chemistry 42: 1925-1930. 